DOI: $10.30612 /$ re-ufgd.v4i8.6928

\title{
A CONTRIBUIÇÃO DO PROJETO DE EXTENSÃO "IV FEIRA DO LIVRO E DA LEITURA DA UFGD” NA FORMAÇÃO ACADÊMICA ${ }^{1}$
}

\author{
La Contribución del Proyecto de Extensión “IV Feria Del Libro y de la Lectura de la UFGD” en \\ la Formación Académica
}

Recebido em 22/09/2017 Aceito em 15/12/2017

\author{
Rodrigo Garófallo Garcia ${ }^{2}$ \\ Cynara Almeida Amaral ${ }^{3}$ \\ Givaldo Ramos da Silva Filho ${ }^{4}$ \\ Wanessa Gonçalves Silva ${ }^{5}$ \\ Raquel Correia de Oliveira ${ }^{6}$ \\ Jéssica Sotolani Manfré ${ }^{7}$
}

Resumo: Relatório de experiência do projeto de extensão da Editora da UFGD. A IV Feira do Livro e da Leitura da UFGD foi realizada no dia $1^{\circ}$ de agosto de 2017, no Centro de Convivência da UFGD. Trata-se de um evento que visa a formação de leitores dos públicos juvenil, adulto, universitário, entre outros. Também busca divulgar e incentivar o trabalho dos autores locais e regionais. Durante o evento foram realizadas exposição, doação e venda de livros da Editora da UFGD, a um preço acessível. As apresentações de leitura de textos produzidos pelos acadêmicos da universidade federal ocorreram nos três períodos. O acesso ao conhecimento promovido pelo evento resultou em impactos sociais positivos na comunidade acadêmica.

Palavras-Chave: Relatório de experiência. Formação de leitores. Autores locais e regionais.

Resumen: Informe de experiencia del proyecto de extensión de la Editora de la UFGD. La IV Feria del Libro y de la Lectura de la UFGD fue realizada el 1 de agosto de 2017, en el Centro de Convivencia de la UFGD. Se trata de un evento que busca la formación de lectores de los públicos,

\footnotetext{
${ }^{1}$ Projeto de extensão desenvolvido pela Editora da UFGD, sob coordenação do Prof. Dr. Rodrigo Garófallo Garcia.

${ }^{2}$ Coordenador da Editora da UFGD (EdUFGD), mestre (2002) e doutor (2005) em Zootecnia pela Universidade Estadual Paulista Júlio de Mesquita Filho (UNESP), com pós-doutorado em Engenharia Agrícola pela FEAGRI/UNICAMP (2012). É tutor no Programa de Educação Tutorial do curso de Zootecnia da UFGD (PET/ZOO) desde setembro de 2007 e diretor de eventos da Fundação APINCO de Ciência e Tecnologia Avícolas (FACTA). E-mail: rodrigogarcia@ufgd.edu.br.

${ }^{3}$ Possui licenciatura plena em Letras (Português, Espanhol e Literatura) pela Universidade Estadual de Mato Grosso Grosso do Sul (2007) e especialização em Estudos Literários pela Universidade Estadual de Mato Grosso do Sul (2013). Atualmente é servidora da UFGD, ocupando o cargo de Revisora de Textos, lotada na Editora da UFGD desde 2015. E-mail: cynaraamaral@ufgd.edu.br.

${ }^{4}$ Possui licenciatura plena em Matemática pela Universidade Estadual de Mato Grosso do Sul (2006) e especialização em Tecnologia de Gestão Pública e Responsabilidade Fiscal pela Escola Superior Aberta do Brasil (2010). Atualmente é Técnico em Assuntos Educacionais da Universidade Federal da Grande Dourados desde 2013. E-mail: givaldofilho@ufgd.edu.br.

${ }^{5}$ Tradutora e intérprete em língua inglesa pela UFMS (2003), mestre (2006) e doutora (2017) em Estudos da Tradução pela UFSC. Revisora de textos da Editora da UFGD desde 2015. E-mail: wanessasilva@ufgd.edu.br.

${ }^{6}$ Mestre em Educação pela Universidade Tuiuti do Paraná (2015), especialista em Metodologia do Ensino Superior pelo Centro Universitário da Grande Dourados (2011) e graduada em Comunicação Social (Jornalismo) pela Universidade Federal de Mato Grosso do Sul (2006). Trabalha como redatora e revisora na Editora da UFGD desde 2009. E-mail: raquelcorreia@ufgd.edu.br.

${ }^{7}$ Acadêmica do curso de Letras (Português, Inglês e Literatura) pela Universidade Estadual de Mato Grosso do Sul. Atualmente é estagiária na Editora da UFGD pelo programa Pró-Estágio da UFGD. E-mail:

jessicahmanfre@gmail.com.
} 
juveniles, adultos, universitarios, etc. También busca divulgar e incentivar el trabajo de los autores locales y regionales. Durante el evento se realizaron exposición, donación y venta de libros de la Editora de la UFGD, con costo accesible. Las presentaciones de lectura de textos producidos por los académicos de la universidad federal ocurrieron durante todo el día. El acceso al conocimiento promovido por el evento resultó en impactos sociales positivos en la comunidad académica.

Palabras Clave: Informe de experiencia. Formación de lectores. Autores locales y regionales.

\section{Introdução}

A primeira Feira do Livro e da Leitura da UFGD foi realizada 14 de junho de 2012; a segunda edição desse evento ocorreu nos dias 20 a 22 de novembro de 2013 e a terceira edição nos dias 14 e 15 de novembro de 2014. Após um período de três anos, a Editora da UFGD (EdUFGD) retomou as atividades com a realização da IV Feira do Livro e da Leitura UFGD, que ocorreu no dia $1^{\circ}$ de agosto de 2017 no Centro de Convivência, localizado no campus universitário. Essa feira faz parte do projeto de extensão realizado pela EdUFGD. De acordo com o Plano Nacional de Extensão Universitária a extensão é:

[...] entendida como prática acadêmica que interliga a universidade nas suas atividades de ensino e de pesquisa com as demandas da maioria da população, possibilita essa formação do profissional cidadão e se credencia cada vez mais junto à sociedade como espaço privilegiado de produção de conhecimento significativo para a superação das desigualdades sociais existentes. (VERÇOSA, 1998, p. 64).

Dessa forma, esse projeto de extensão busca divulgar e incentivar o trabalho dos autores locais e regionais. Também visa à formação de leitores dos públicos juvenil, adulto e universitário. $\mathrm{O}$ coordenador editorial da EdUFGD, professor Rodrigo Garófallo Garcia destaca que a prática da leitura:
[...] é uma das oportunidades mais incríveis para o desenvolvimento pessoal e profissional. Por meio dela, podemos ultrapassar as fronteiras do imaginário e descobrir novos universos sem precisarmos sair do lugar. $\mathrm{O}$ hábito de ler nos permite adentrar num processo de expansão e a abertura intelectual para infinitas possibilidades. Fonte de verdadeira riqueza, o livro constitui-se como um atalho para o despertar imaginativo e aprimoramento dos diversos saberes, e a leitura torna-se a ferramenta essencial na trilha do conhecimento. (GARCIA, 2016, p. 5).

Durante o evento foram realizadas exposição, doação e venda de livros do catálogo da Editora da UFGD a um preço acessível e o pré-lançamento da obra comemorativa de 10 anos da EdUFGD, intitulada A importância da leitura: crônicas, contos, poesias. Os textos dessa obra foram produzidos pelos acadêmicos da UFGD, que apresentaram a leitura de seus contos, crônicas e poesias durante a realização da feira. Após a leitura, houve um bate-papo com alguns autores da obra, que contaram sobre sua inspiração para a escrita e agradeceram à EdUFGD pela oportunidade de publicação. Sobre a obra comemorativa, Rodrigo Garcia elucida que:

Ao abrir espaço para a reflexão e expressão dos alunos de graduação da UFGD sobre a leitura, a Editora, ciente de seu papel na formação acadêmica, reúne, na obra que ora apresenta à comunidade, contos, crônicas e poesias para coroar uma década de muito trabalho e dedicação. (GARCIA, 2016, p. 7). 


\section{A Editora da UFGD}

Criada em outubro de 2006, desde o início a Editora da UFGD se dedica à publicação da produção intelectual da universidade, divulgando os resultados das pesquisas acadêmicas de seus servidores docentes e técnicos-administrativos e de seus pós-graduandos, bem como as obras de pesquisadores não inseridos no quadro de servidores da UFGD.

Estimulando a produção intelectual voltada à comunidade interna e externa, a EdUFGD apoia a organização, a publicação, a divulgação, a distribuição e a venda de obras bibliográficas da UFGD. Com dez anos de existência, a Editora soma mais de 180 obras publicadas, dentre elas livros, e-books e cadernos acadêmicos (material para uso em sala de aula). ${ }^{1}$

\section{Feira do Livro e da Leitura da UFGD}

Fruto do projeto de extensão realizado pela Editora da UFGD e coordenado pelo Prof. Dr. Rodrigo Garófallo Garcia, a IV Feira do Livro e da Leitura da UFGD ocorreu no Centro de Convivência da Unidade 2 da UFGD, em Dourados, durante os três períodos do dia $1^{\circ}$ de agosto de 2017.

Este evento, voltado à comunidade acadêmica da UFGD, visa à formação de leitores de diferentes segmentos, além de divulgar e incentivar o trabalho de autores locais e regionais.

Fizeram parte da organização e da programação da IV Feira do Livro e da Leitura da UFGD: o coordenador editorial Rodrigo G. Garcia; os técnicos administrativos da EdUFGD - Cynara A.
Amaral; Givaldo Ramos da Silva Filho; Raquel Correia de Oliveira e Wanessa Gonçalves Silva -; a estagiária Jéssica Sotolani Manfré; e os autores da obra $A$ importância da leitura: crônicas, contos, poesias. Veja o cartaz do evento na Figura 1:

Figura 1 - Cartaz de divulgação do evento.

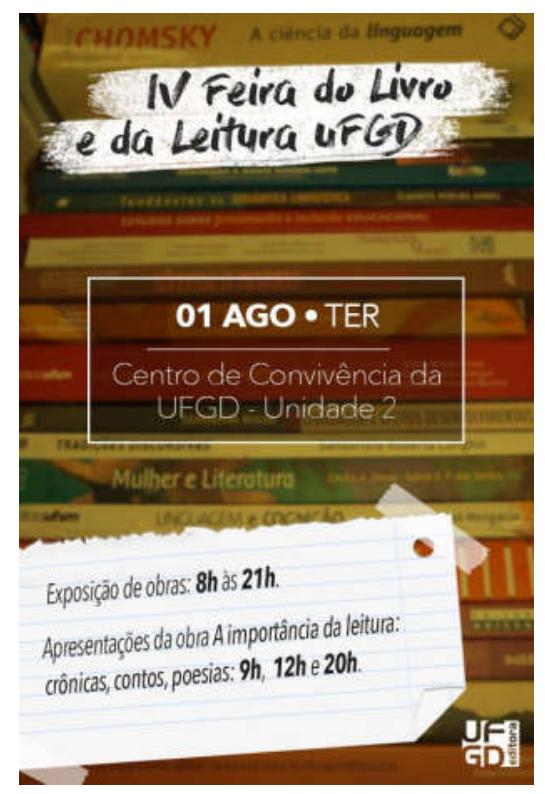

A IV Feira do Livro e da Leitura da UFGD foi bastante divulgada na mídia, o que rendeu visibilidade do projeto. O Jornal do canal de televisão RIT foi até o Centro de Convivência e cobriu o evento no período matutino. O coordenador editorial Rodrigo foi entrevistado e a autora a Eliane foi filmada, fazendo a tradução do seu poema em libras (JORNAL DA RIT, 2017), veja a figura 2: 
Figura 2 - Entrevista com o prof. Rodrigo G. Garcia.

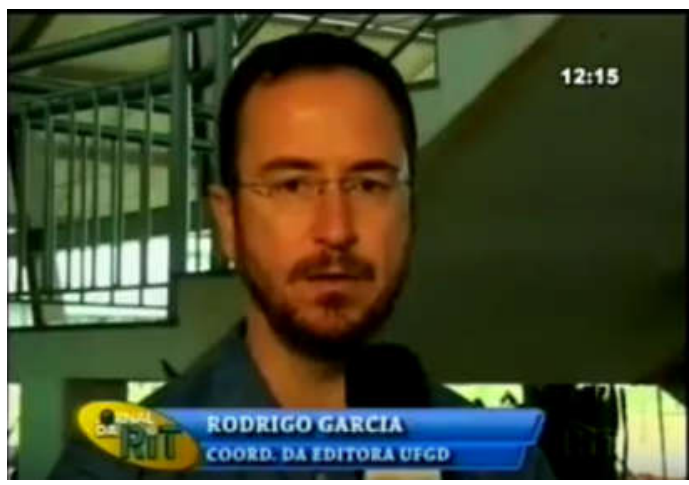

Fonte: JORNAL DA RIT, 2017.

O projeto de extensão da Editora da UFGD também teve destaque com duas notícias no Portal da UFGD (UFGD, 2017a, 2017b). A Associação Brasileira das Editoras Universitárias (ABEU) divulgou o evento da EdUFGD e também informou sobre a presença da Editora na abertura do VIII Seminário de Extensão Universitária da Região Centro-Oeste (SEREX), com divulgação e venda de livros (ABEU, 2017), ocorrido no dia anterior à Feira. Outros jornais locais também noticiaram a IV Feira do Livro e da Leitura da UFGD em suas páginas eletrônicas, como o Diário MS (2017), Dourados News (2017) e Midiamax (2017).

Em seus depoimentos, os professores da UFGD que visitaram o stand da Editora feira reconhecem a relevância deste projeto de extensão da EdUFGD, como pode ser observado a seguir:

Depoimento 1: "Tenho acompanhado com especial interesse a presença da Editora da UFGD em eventos intelectuais. Considero de fundamental importância sua atuação nesse cenário. $\mathrm{O}$ convívio dos acadêmicos com a produção intelectual da Universidade tem efeitos muito positivos tanto para os leitores quanto para os pesquisadores que publicam. Com efeito, vivemos rodeados de instituições particulares que privilegiam o investimento em seus prédios e na propaganda cotidiana dos serviços que prestam. E qual a propaganda mais interessante que nossa Universidade pública tem para fazer? Sem dúvida alguma são as pesquisas avançadas dos seus professores. O investimento que o país faz nesse trabalho é grande e precisa ser mostrado. A publicação é o patrimônio universitário de maior consequência, pois faz multiplicar o conhecimento. Portanto, vejo com muito bons olhos o cuidado que se tem na apresentação de nossos livros e na presença das obras nos eventos que a Universidade promove. Sem dúvida alguma, isso trará bons frutos a médio e longo prazos. Parabéns aos responsáveis pela Editora da UFGD". (Prof. Dr. Paulo Custódio de Oliveira - FACALE).

Depoimento 2: "Há cinco anos eu participo do Festival Internacional de Literatura de Parati-RJ. Por quatro vezes, liderei a ida dos alunos e das alunas do curso de Letras da UFGD para este festival. O que me impulsiona é a possibilidade de oferecer uma vivência ampla aos nossos estudantes. Foi com o mesmo entusiasmo que eu aceitei participar da IV Feira do Livro e da Leitura da UFGD. A organização deste evento tem motivos para se orgulhar da proposta. A comunidade universitária (UFGD, UEMS, UNIGRAN) e a comunidade douradense, de maneira geral, vivenciaram dias em que os livros foram os protagonistas. Ao oportunizar esta vivência, os organizadores cumprem com o seu papel social e educativo. Eu quero mais feiras de livros!". (Prof. ${ }^{a}$ Dr. ${ }^{a}$ Alexandra Santos Pinheiro e Tutora PETLetras-UFGD).

Depoimento 3: "Aprender a aprender é um exercício vivencial construído cotidianamente, cheio de significados e até de sentidos indeléveis. Para construir esses sentidos indeléveis é preciso participar, sentir-se pertencente e contextualizado. Visitei a Feira do Livro e da Leitura da UFGD e me senti contextualizada e encantada com o momento. Espaço rico de conhecimentos e informações, com infinitas possibilidades ao aprender a aprender". (Prof. ${ }^{a}$ Dr. ${ }^{a}$ Mirlene Damázio Coordenadora do NuMIAc). 


\section{Exposição e vendas de livros}

A EdUFGD realizou exposição e vendas de obras. Cerca de 90 títulos foram expostos e disponibilizados para venda pela metade do preço do catálogo. Durante a IV Feira do Livro e da Leitura da UFGD, livros foram vendidos com o valor promocional de $50 \%$ de desconto.

Todos os que visitaram o stand puderam apreciar as obras publicadas pela Editora. Também tiveram a oportunidade de conhecer os novos títulos que foram publicados nos últimos três anos, inclusive algumas obras que seriam lançadas no mês de agosto, em evento próprio.

A comunidade acadêmica teve a oportunidade de adquirir gratuitamente $\mathrm{o}$ catálogo impresso da Editora e foi informada sobre o catálogo on-line, que possibilita o acesso gratuito e o download das obras em formato digital: livros ${ }^{1}$; cadernos acadêmicos; e-books ${ }^{2}$. Confira as fotos do evento a seguir (figuras de 3 a 9):

Figura 3 - Exposição e venda no período matutino.

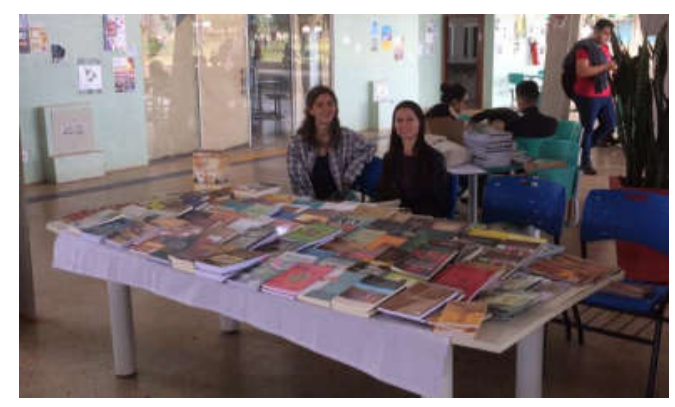

${ }^{1}$ Conheça o catálogo on-line da Editora da UFGD através do link:

$<$ https://www.ufgd.edu.br/setor/editora/catalogo $>$.
Figura 4 - Entrega de catálogos a acadêmicos.

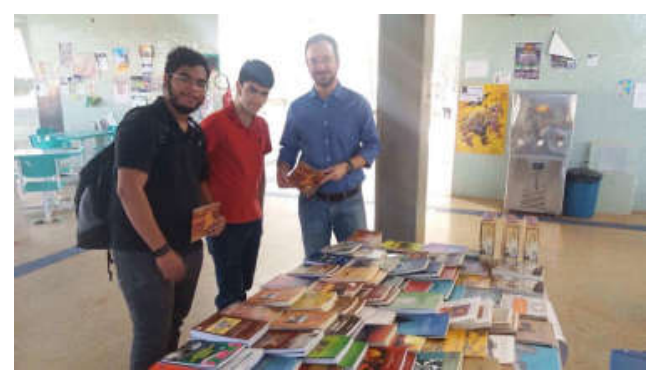

Figuras 5 e 6 - Exposição e vendas de livros no período vespertino.

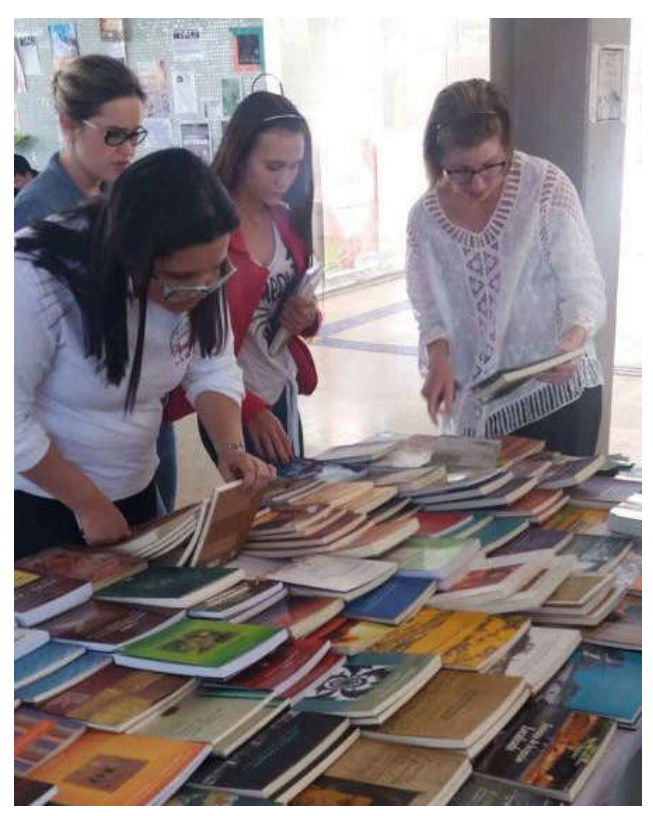

${ }^{2}$ Os e-books podem ser acessados a partir link:

$<$ https://www.ufgd.edu.br/setor/editora/e-books $>$. 


\section{REดLIZZAÇĂ○}

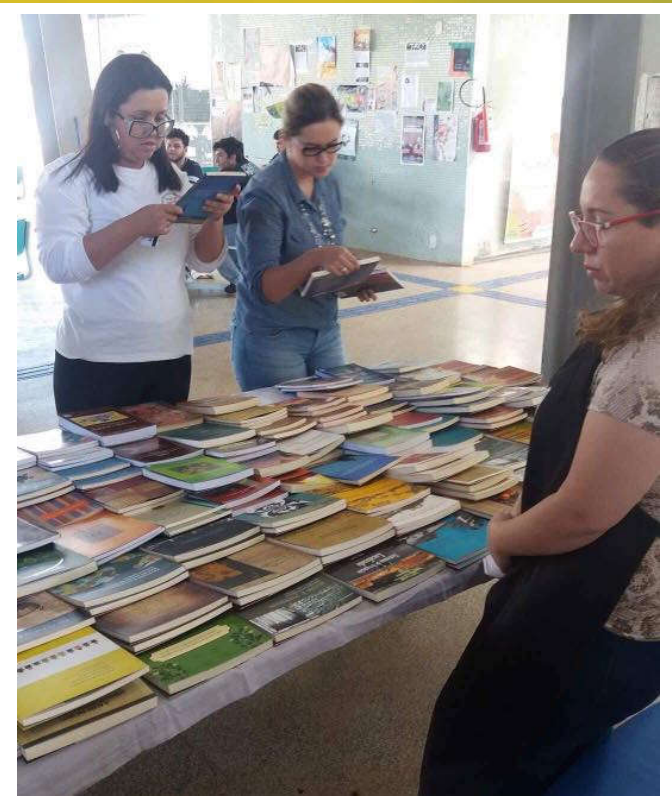

Figuras 7 e 8 - Exposição e vendas de livros.
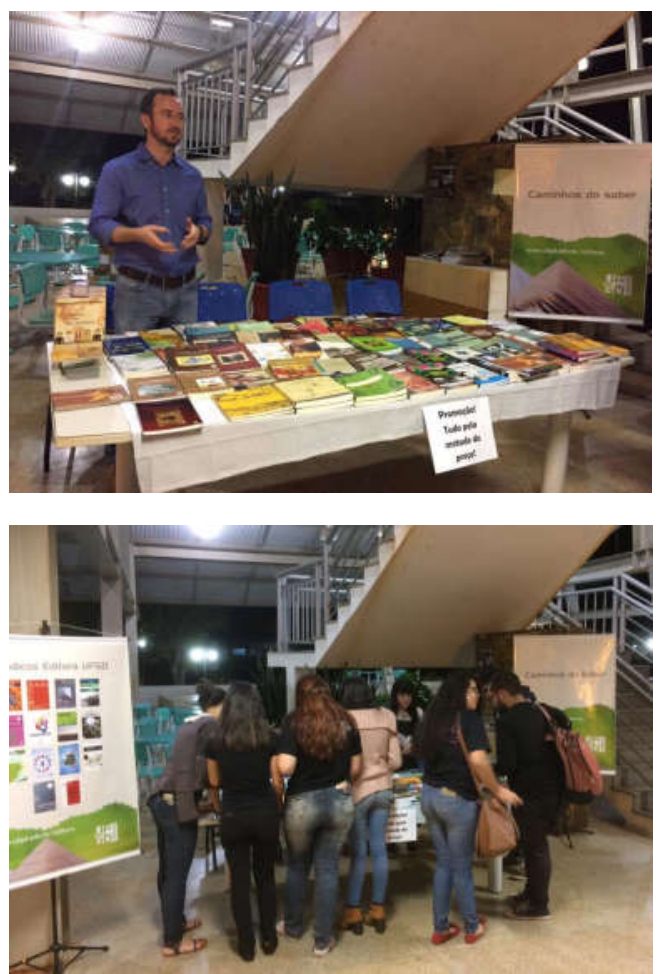

Figura 9 - Exposição e venda

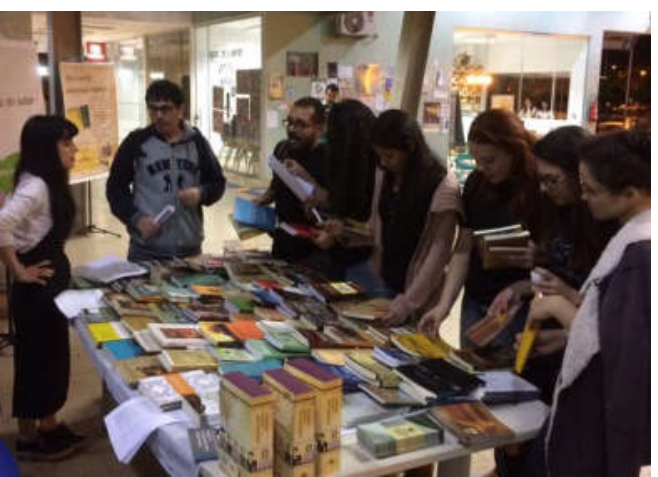

\section{Política de doação de livros}

A EdUFGD possui uma política de doação de livros, possibilitando o acesso às obras publicadas pela Editora, fomentando a leitura e propagando o conhecimento. Essa política de doação por si só exerce a ação de extensão da EdUFGD.

Sobre a política de doação de livros, a Editora informa:

Terão direito a retirar 2 (dois) exemplares (de títulos diferentes) por ano: alunos beneficiados pelo Programa de Assistência Estudantil; alunos do Programa Pró-estágio da UFGD; alunos beneficiados pelos programas de bolsas de pesquisa, de extensão ou de ensino; programa de educação tutorial (PET); alunos dos programas de pós-graduação; docentes e técnicos administrativos da UFGD. (EDUFGD, [2015]).

Durante a IV Feira do Livro e da Leitura da UFGD, a Editora divulgou a política de doação de livros e o número de doações realizadas foi surpreendente. No total, 73 livros foram doados pela EdUFGD ao público da UFGD no dia $1^{\circ}$ de agosto. Observe o gráfico 1 a seguir. 


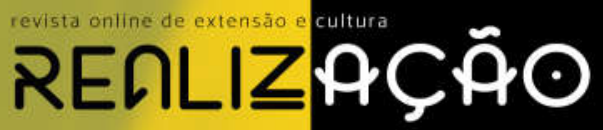

Gráfico 1 - Doações realizadas pela EdUFGD durante a IV Feira do Livro e da Leitura da UFGD.

\section{Quantidade de livros doados}

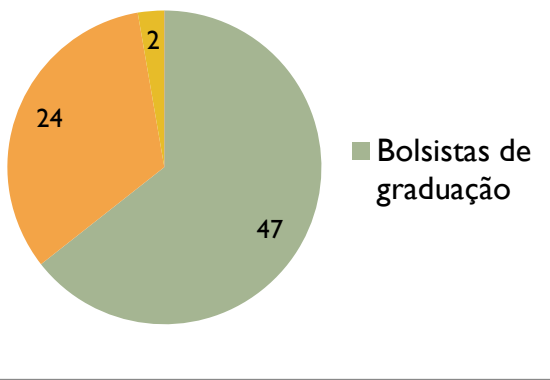

Fonte: Elaboração própria.

Percebe-se que os discentes de graduação foram os que mais se beneficiaram com a divulgação da política de doação durante a realização do evento. Os acadêmicos bolsistas de graduação receberam 47 livros produzidos pela EdUFGD. Já os pós-graduandos, em sua maioria mestrandos, receberam 24 exemplares. Os docentes da UFGD receberam dois exemplares. Observa-se que não houve doações aos técnicos administrativos.

Acredita-se que o local escolhido para a realização do evento, o Centro de Convivência da UFGD, também contribuiu para que a comunidade acadêmica tivesse acesso ao stand da Editora, facilitando as vendas e as doações de livros. No próximo gráfico, verifica-se a relevância da IV Feira do Livro e da Leitura da UFGD e o efeito da divulgação da política de doação de livros. Observe o gráfico 2:

Gráfico 2 - Doações realizadas pela EdUFGD de $1^{\circ}$ de janeiro a $1^{\circ}$ de agosto de 2017.

Fonte: Elaboração própria.

Esse gráfico compara as doações realizadas pela Editora ao público da UFGD (bolsistas de graduação, pós-graduandos, técnicos administrativos e docentes), através do programa de doações. Nota-se que durante a IV Feira do Livro e da Leitura da UFGD, realizada no dia $1^{\circ}$ de agosto, o número de doações aumentou consideravelmente em relação aos meses anteriores. Observe as doações realizadas de acordo com as figuras 10 e 11:

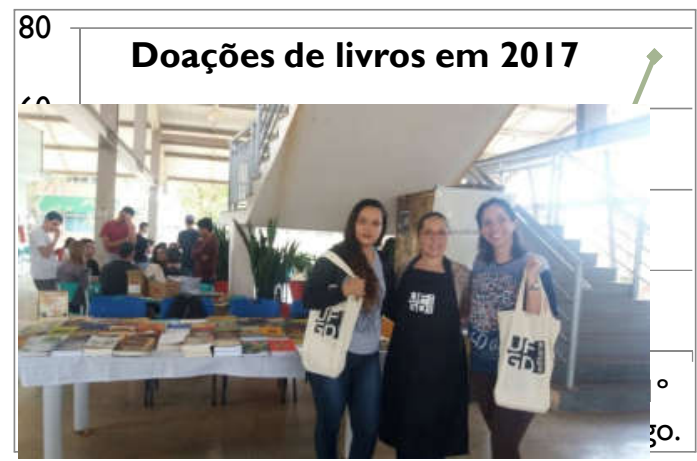

Figura 10 - Doações de livros da EdUFGD.

Figura 11 -Doação de livros.

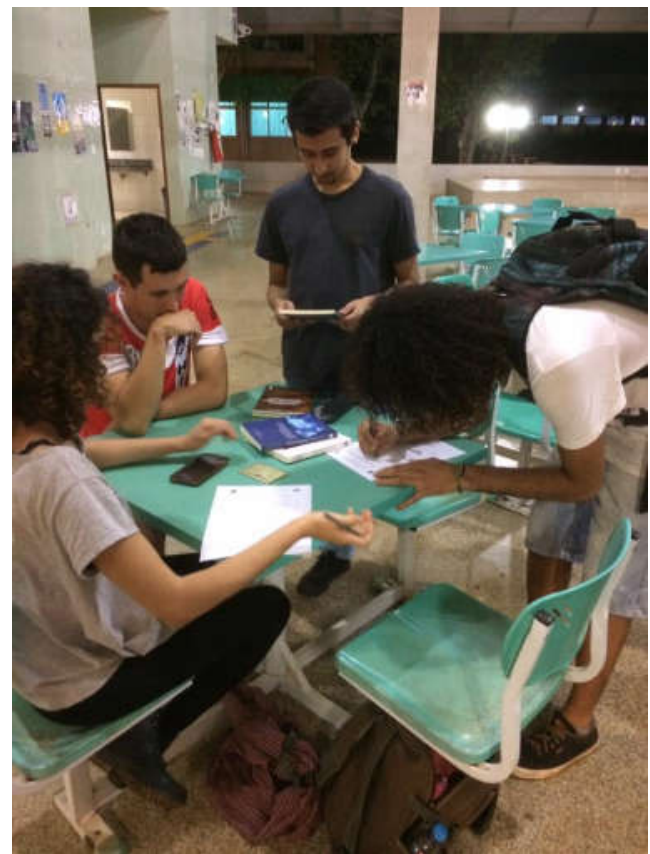

Em seus depoimentos, acadêmicas que visitaram a IV Feira do Livro e da Leitura da UFGD, beneficiadas com a política de doação de livros, expõem suas impressões sobre o evento, como podemos ver a seguir:

Depoimento 4: "Sobre a IV Feira do Livro e da Leitura realizada pela Editora da 
UFGD no Centro de Convivência, achei muito produtiva, pois ajuda a divulgar as pesquisas e trabalhos da Universidade, dos alunos e professores, aproveitei para adquirir dois livros [doação] muito interessantes sobre literatura. Aproveito para parabenizar aos organizadores e colaboradores pelo ótimo atendimento e atenção". (Hélia Marcia Kovalski Castilho Teno - Egressa do PPG Letras/FACALE/UFGD).

Depoimento 5: "A feira de livros da Editora da UFGD foi duplamente proveitosa para mim. Primeiramente porque os livros disponibilizados são obras importantes que nos ajudarão no decorrer de nossas pesquisas e estudos. O outro motivo é que, através da feira, fiquei sabendo que alunos de iniciação científica e de pós-graduação da UFGD têm direito a receber dois livros ao ano. Somente uma editora de excelência como a Editora da UFGD poderia ter a sensibilidade de oferecer suas obras gratuitamente aos alunos. Muito Obrigada". (Patrícia P. Nascimento - Mestranda em Literatura/FACALE/UFGD).

Depoimento 6: "Desde que participo de eventos acadêmicos na cidade de Dourados - MS percebo a presença marcante da Editora da UFGD. Como foi o caso do XI Encontro Proler, do qual faço parte como organizadora, em que a Editora fez uma doação de material. Então, foi com enorme satisfação que pude marcar presença na IV Feira do Livro e da Leitura da UFGD, que contou com lançamento de livro, declamações e doações (que, inclusive, fui agraciada com dois exemplares maravilhosos) para estudantes de pósgraduação. Parabéns ao professor Rodrigo, à Cynara e à toda equipe editorial". (Kelly Mara Soares Dornelles - Egressa do PPG Letras/FACALE/UFGD).

\section{Apresentação de leitura}

A apresentação de leitura foi realizada por alguns alunos autores da obra comemorativa dos 10 anos da Editora, intitulada A importância da leitura, publicada em 2016. Este livro também está disponível para download no catálogo on-line. ${ }^{1}$

No período matutino apresentaram a leitura:

a) Eliane Francisca Alves da Silva Ochiuto, autora da poesia "Meus olhos leem". A autora é acadêmica do curso de LetrasLibras $(\mathrm{EaD})$ e intérprete. A estagiária da EdUFGD, Jéssica Sotolani Manfré, realizou a leitura do texto e a autora Eliane fez a interpretação para Libras. (Figura 12).

b) Matheus Heindrickson Prudente dos Santos leu seu poema "Da importância da Leitura na vida em sociedade (ou Textão para Facebook". O autor é acadêmico do curso de Ciências Econômicas (FACE). (Figura 13).

c) Bruna Corrêa da Rosa, autora do conto "História sem data". A autora é acadêmica do curso de Letras (FACALE). (Figura 14).

d) Juliana da Cruz Prado, que leu sua crônica "De leitor para leitor". A autora é acadêmica do curso de Ciências Econômicas (FACE). (Figura 15). 


\section{REALIZ̈AÇă̊}

Figura 12 - Estagiária Jéssica e autora Eliane.

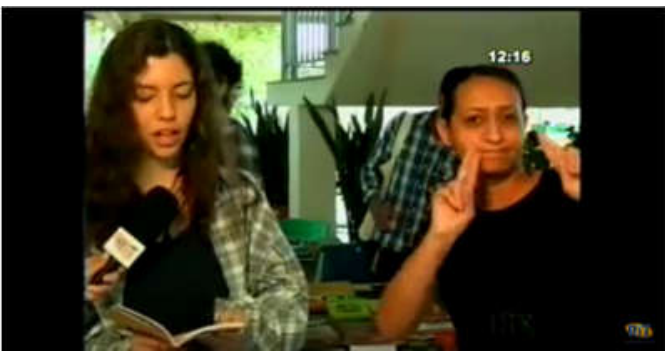

Fonte: JORNAL DA RIT, 2017.

Figura 13 - Autor Matheus H. P. dos Santos.

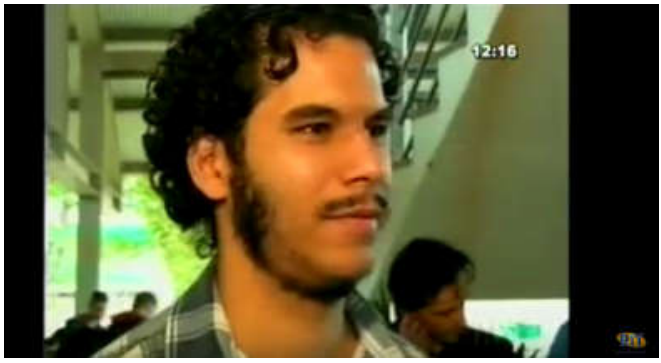

Fonte: JORNAL DA RIT, 2017.

No período vespertino apresentaram a leitura:

Figura 14 - Autora Bruna e Cynara

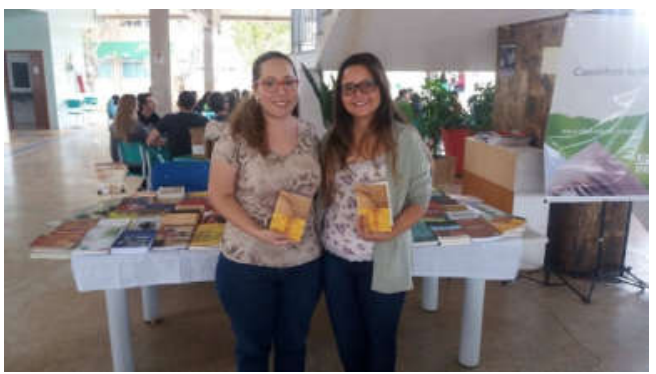

Figura 15 - Autora Juliana, acadêmicos e Cynara.

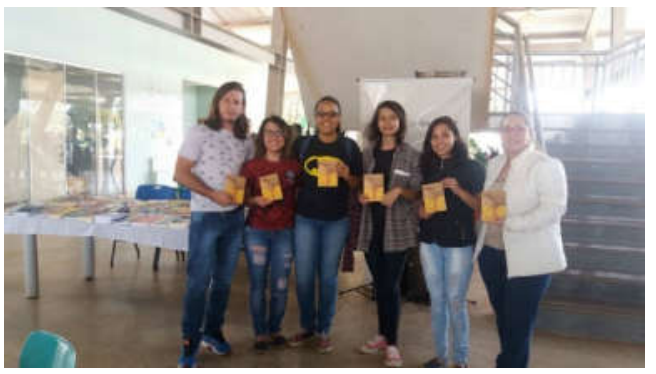

No período noturno apresentaram a leitura:

a) Francieli Efigenio Cabreira, que leu seu poema “Amplitude". A autora é acadêmica do curso de Letras (FACALE);

b) João Alexandre Alves dos Santos, que leu seu poema "Isso é mais que 'apenas ler"”. O autor é acadêmico do curso de Letras (FACALE);

c) Lilian Siqueira e Silva, com leitura de sua crônica "A lenda do meu nome". A autora é acadêmica do curso de Engenharia de Produção (FAEN);

d) Lucas Menezes de Moraes, que leu seu conto "Os prantos". O autor é acadêmico do curso de Letras (FACALE);

e) Vinicius Gonçalves Mazzini, com leitura de seu poema "Sobre (a) vida". O autor é acadêmico do curso de Letras (FACALE).

Observe as fotos das apresentações de leitura no período noturno nas figuras 16 a 20: 


\section{REดLIZZAÇĂ○}

Figura 16 - Leitura no Centro de Convivência

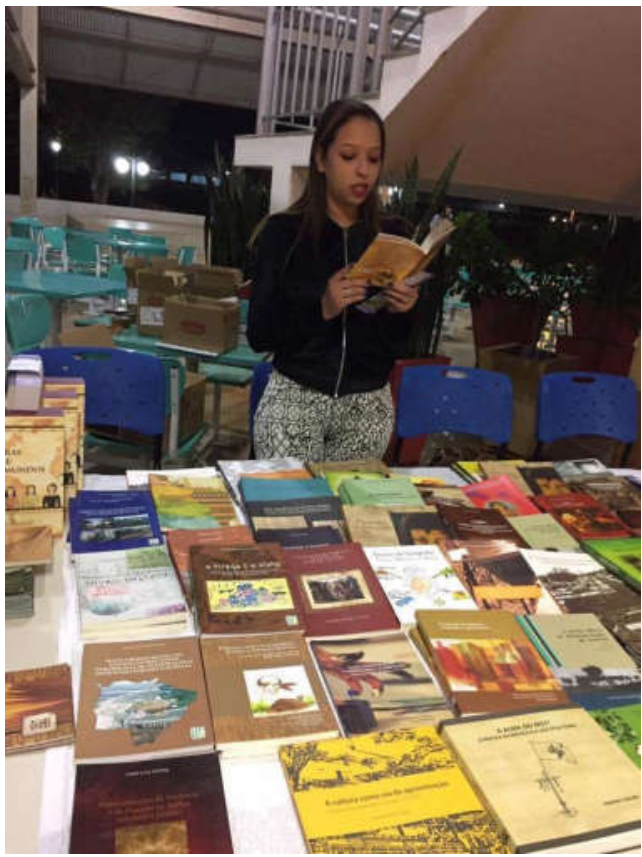

Figura 17 - leitura no Centro de Convivência

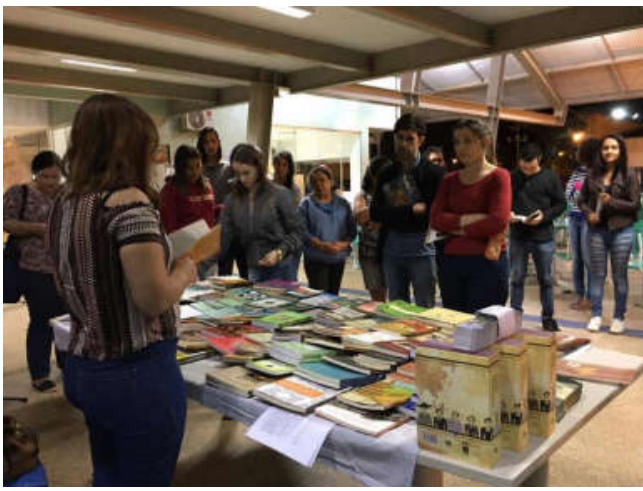

Figuras 18- Leitura no Centro de Convivência.

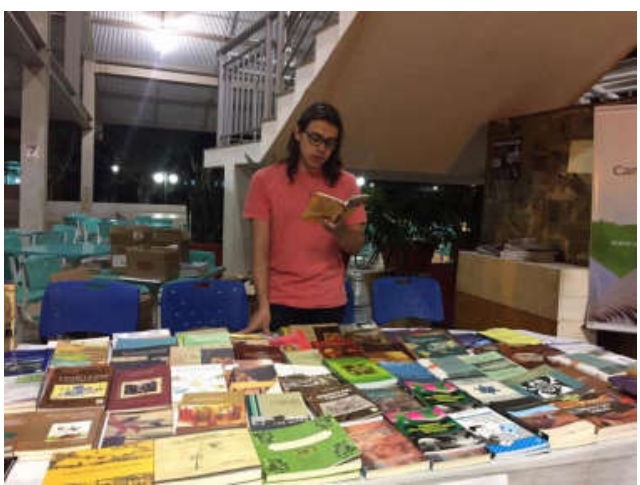

Figuras 19 e 20 - Leitura no Centro de Convivência.
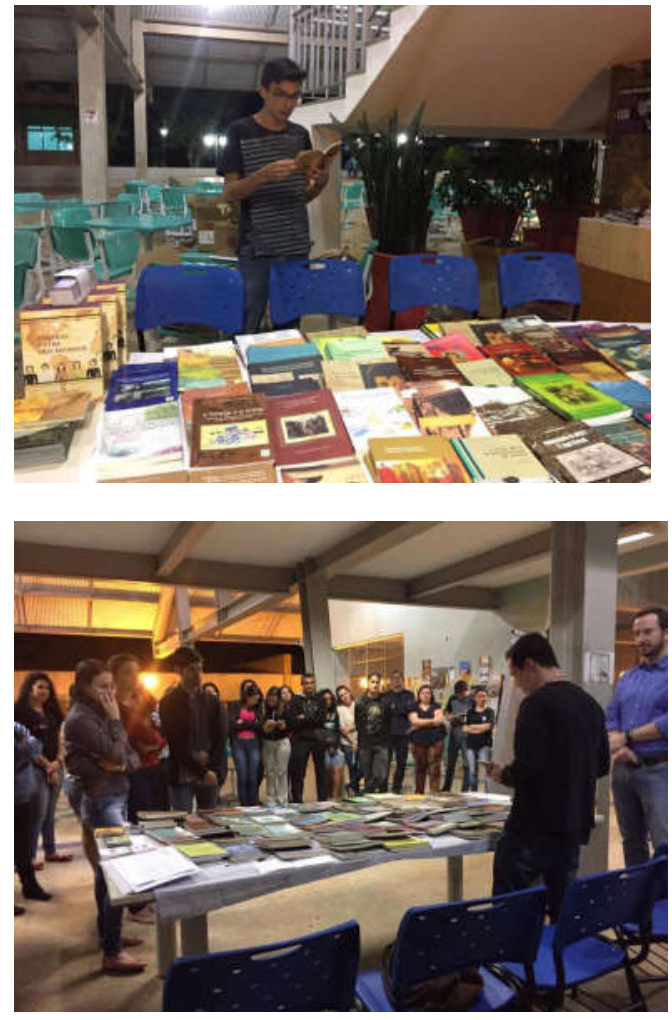

Fonte: Acervo da EdUFGD.

O relato de experiência de três autoras que apresentaram a leitura de seus textos durante o pré-lançamento da obra comemorativa de 10 anos da EdUFGD pode ser observado nos seguintes depoimentos:

Depoimento 7: "É sempre uma honra fazer parte de uma Universidade tão acolhedora como a UFGD. Participar da feira literária foi uma experiência gratificante, uma oportunidade única dada pela Editora. $\mathrm{O}$ carinho com que fui tratada naquele dia foi essencial para apesentar o meu texto com tranquilidade e confiança. Minha primeira publicação não poderia ser feita em outro lugar. Obrigada a todos os envolvidos por serem o motor de nossos sonhos. (Franciele Cabreira - acadêmica/autora).

Depoimento 8: "Meu nome é Juliana, tenho 21 anos e sou acadêmica do curso de Economia. Desde pequena pude desenvolver o hábito pela leitura e todo o seu mundo mágico. Então, ter a oportunidade de escrever sobre A 
importância da Leitura e participar da IV Feira do Livro e da Leitura da UFGD foi realmente muito significativo e enriquecedor". (Juliana Prado acadêmica/autora).

Depoimento 9: "A IV Feira do Livro e da Leitura UFGD é um evento de suma importância para a comunidade acadêmica. Fazer parte da coleção de obras em comemoração aos 10 anos da Editora, como autora do poema 'Meus olhos leem', foi muito gratificante e prazeroso. Por ser surda, foi importante a apresentação do mesmo em Libras (Língua Brasileira de Sinais). para que meus amigos surdos também pudessem entender o que estava sendo transmitido nas simples palavras contidas no poema". (Eliane Francisca Alves da Silva Ochiuto acadêmica/autora).

A estagiária da Editora da UFGD também relata sua experiência na organização e participação da IV Feira do Livro e da Leitura da UFGD:

Depoimento 10: “A experiência de participar da IV Feira do Livro foi muito importante. Levamos o material da Editora para dentro da comunidade acadêmica. Pessoas de qualquer área do conhecimento poderiam passar e procurar uma obra que fosse relacionada a seus interesses. Muitas doações a bolsistas foram feitas nesse dia. Aproveitamos o evento também para divulgar o lançamento coletivo de obras que estava perto de acontecer. Gratidão por poder fazer parte de tudo isso e contribuir para a disseminação do conhecimento". (Jessica Sotolani Manfré, estagiária da EdUFGD e acadêmica de Letras/Inglês na UEMS).

\section{Ações e resultados}

Os objetivos propostos e alcançados através do Projeto de Extensão da EdUFGD, foram:

a) Dar continuidade aos eventos realizados nos anos de 2012, 2013 e 2014; b) Divulgar as obras e autores da Editora da UFGD e incentivar a leitura;

c) Permitir a participação e integração de diferentes públicos, como autores, editores, acadêmicos, estudantes do ensino médio, técnicos, professores do ensino médio e o público em geral;

d) Promover a comercialização de livros;

e) Possibilitar aos autores o lançamento e/ou apresentação de suas obras;

f) Criar espaço para a leitura;

g) Estimular a publicação;

h) Promover a interação entre universidade e sociedade;

i) Promover a doação de livros de acordo com a política institucional;

j) Criar um espaço para a troca de experiências entre os leitores.

Os resultados da ação de extensão foram positivos:

a) Com a realização da Feira do Livro foi possível apresentar a produção técnicocientífica à comunidade acadêmica;

b) Houve integração entre as áreas do conhecimento, pois foram contempladas, o que proporcionou um caráter interdisciplinar ao evento;

c) Foi realizado o pré-lançamento do Livro Comemorativo dos 10 anos da EdUFGD, intitulado A importância da leitura;

d) A realização do evento permitiu capacitar a equipe da Editora no que diz 
respeito à organização de eventos e atendimento ao público;

e) A exposição das obras da Editora promoveu a difusão e divulgação do conhecimento;

f) $\mathrm{O}$ evento trouxe bons resultados à comunidade acadêmica, a qual pode ter acesso ao acervo da EdUFGD; g) A facilitação ao acesso ao conhecimento promovida pelo evento certamente trouxe impactos sociais à comunidade acadêmica.

O evento obteve o sucesso desejado e deu grande visibilidade aos trabalhos e serviços prestados pela EdUFGD. A aceitação e repercussão do evento permitirão o planejamento de sua próxima edição em 2018.

\section{Referências}

ABEU. Editora da UFGD marca presença na IV Feira do Livro e da Leitura UFGD. São Paulo, 2017. Disponível em: <http://www.abeu.org.br/farol/abeu/blog/noticias/editora-da-ufgdmarca-presenca-na-iv-feira-do-livro-e-da-leitura-ufgd/9940>. Acesso em: 5 set. 2017.

DIÁRIO MS. A UFGD promove IV Feira do Livro e da Leitura hoje. Dourados, 2017. Disponível em: < http://diarioms.com.br/ufgd-promove-iv-feira-do-livro-e-da-leitura-hoje/>. Acesso em: 5 set. 2017.

DOURADOS NEWS. Editora promove Feira do Livro e da Leitura terça-feira em Dourados. Dourados, 2017. Disponível em: <http://www.douradosnews.com.br/dourados/editora-promovefeira-do-livro-e-da-leitura-terca-feira-em-dourados-30-07-2017-08>. Acesso em: 5 set. 2017.

EDUFGD. Doações de livros. Dourados, [2015]. Disponível em: $<$ http://portal.ufgd.edu.br/setor/editora/doacoes-livros>. Acesso em: 13 set. 2017.

GARCIA, R. G. Apresentação. In: BUTTINI, A. P. O. et al. A importância da Leitura: crônicas, contos e poesias. Dourados: Ed. UFGD, 2016.

JORNAL DA RIT. Reportagem sobre a IV Feira do Livro e da Leitura da UFGD. Dourados, 2017. Disponível em: <https://www.youtube.com/watch?v=nnHbaySZqrY>. Acesso em: 5 set. 2017. Reportagem veiculada na primeira edição do Jornal da RIT de 1 de agosto de 2017.

MIDIAMAX. Universidade realiza feira do livro e da leitura dia primeiro de agosto. Dourados, 2017. Disponível em: <http://www.midiamax.com.br/literatura/universidade-realizafeira-livro-leitura-dia-primeiro-agosto-348794>. Acesso em: 5 set. 2017.

UFGD. Dia $1^{\circ}$ de agosto tem Feira do Livro e da Leitura no Centro de Convivências. Dourados, 2017a. Disponível em: <https://portal.ufgd.edu.br/noticias/dia-1-de-agosto-tem-feirado-livro-e-da-leitura-no-centro-de-convivencias>. Acesso em: 5 set. 2017.

. Livros com descontos e apresentações literárias foram destaque na IV Feira do Livro e da Leitura da UFGD. Dourados, 2017b. Disponível em: 
$<$ https://portal.ufgd.edu.br/noticias/livros-com-desconto-e-apresentacoes-literarias-foramdestaque-na--iv-feira-do-livro-e-da-leitura-ufgd>. Acesso em: 5 set. 2017.

VERÇOSA, E. G. (Org.). Educação superior e políticas públicas: a implantação da nova LDB em debate. Maceió-AL: UFAL, 1998, p. 64. 